\title{
Analysis on Stress Levels of Hearing-Impaired and Physically Handicapped Sportspeople Based on Certain Demographic Variables
}

\author{
Sedef Habipoglu ${ }^{1}$ \\ ${ }^{1}$ Faculty of Sport Sciences, Nigde Omer Halisdemir University, Nigde, Turkey \\ Correspondence: Sedef Habipoglu, Faculty of Sport Sciences, Nigde Omer Halisdemir University, Nigde, \\ Turkey. E-mail: skurt@ohu.edu.tr
}

Received: January 2, 2020

Accepted: January 31, 2020 Online Published: February 24, 2020

doi:10.5539/jel.v9n2p116

URL: https://doi.org/10.5539/jel.v9n2p116

\begin{abstract}
The purpose of this study is to analyze the stress levels of hearing-impaired and physically handicapped elite licensed sportspeople at the national team level.

Population of the research has been licensed handicapped sportspeople in Central Anatolia, and the sample group has consisted of 100 participants from this population, who were selected through the convenience sampling method.

The questionnaire used in this research consists of two parts. The first part is comprised of demographics questions for determining personal information. In the second part, a stress scale has been used so that stress levels experienced with teammates and trainers can be determined. It has been adapted from the scale used by Yalçın (2009). The scale consists of 10 statements for determining the stress level. These statements were prepared based on the 5-point Likert scale, sorted as "never $=1$, rarely $=2$, sometimes $=3$, often $=4$, very often $=5$ ". And reliability of the data has been tested with Cronbach's Alpha coefficient $(\alpha=0.68)$.

Normality distribution tests, the Kolmogorov-Smirnov and Shapiro-Wilk tests, have been carried out in order to determine whether the data initially presented a normal distribution at the analysis stage. The data were determined to have a normal distribution, and within this purpose, Independent Samples $t$ Test for paired comparisons and One-Way Anova test for multiple comparisons were conducted.

As a result, it has been determined that sports affect stress levels positively, there is a significant difference in stress levels of hearing-impaired and physically handicapped sportspeople and there is no significant difference between gender and marital status, educational background and disability.
\end{abstract}

Keywords: physically handicapped sportspeople, hearing-impaired sportspeople, stress

\section{Introduction}

Stress, known as one of the most important problems and illnesses of today, is a phenomenon existing in all people. Many people are unaware of the fact that they are in such a state. Not only bad situations, but also good situations in our lives are triggered by stress. Many factors in our lives cause stress. Even a slight change in our body health causes stress. Upon consideration, mental phenomena cause stress at least as much as real and physical changes. Comments, criticisms, emotions and thoughts are some examples of such mental phenomena (Güçlü, 2001).

Stress can briefly be defined as our entirety of our reactions at our desires. Many of us believe that stress is instilled into our lives by others. However, this is not the case. Stress is an action against the circumstances created by our senses and perceived desires. In this sense, stress is a reaction at the stimulus creating various physical and mental desires in a person (Çukur, 2001).

Stress is not scientifically defined as a negativity. However, it is considered as a phenomenon that makes our daily life difficult and negatively affects our health. Stress, which is identified with the words such as fear, anxiety, dilemma, hassle and problem, should not be considered as a bad and negative phenomenon in general (Çakır, 2006).

Stress can be caused completely by one's own motives. Individuals tend to see what they think and desire. People can turn a very negative situation into a very positive one, and vice versa, with thoughts. Therefore, 
individuals' characteristics appear to be a cause for stress (İstengel, 2006).

Stress is significantly influential on sportspeople, as is for everyone. Stress can negatively effect, or even injure, physical states as well as efforts and wins, pleasures and enjoyments of sportspeople. Stress triggers negative thoughts and frustrates sportspeople. For example, stress may result in loss of self-esteem through the feeling of incapability. Sportspeople are frustrated by psychological stress, thus failing to exhibit their abilities gained throughout the years. Stress may cause injuries and end careers of sportspeople. Stress is an unobservable disorder. This may reveal itself in overtraining (as cognitive, affective, social and physiological exhaustion). Negative outcomes caused by stress is an important threat for not only sportspeople but also trainers and the assisting team, since stress may cause significant damages to such individuals as well as sportspeople. Stress management practices must be comprehended in order to avoid such negative effects (Altungül, 2006).

In this study, stress levels of hearing-impaired and physically handicapped sportspeople are examined. Addressing and concluding stress levels of handicapped sportspeople as well as circumstances causing stress and taking precautions in accordance with such conclusions are of importance for planning.

\subsection{Hearing Deficiency}

Hearing is one of the basic senses that play a highly important role in our lives and ensure communication with our environment, and it is involved in both mental and linguistic development of individuals. And hearing deficiency results in the loss of sense caused by damages on hearing or auditory nerves (Tüfekçioğlu, 2003). Akçamete (1999) stated that hearing deficiency has a severity range from low to high intensity, including deaf and hard-hearing subgroups. A deaf individual is defined as a person that perceives linguistic concepts through auditory senses with or without a hearing aid, and an individual hard of hearing is defined as a person that has a remnant of hearing ability adequate for meeting their needs and can perceive linguistic concepts with hearing aids programmed according to the hearing level.

\subsection{Hearing Impairment}

Hearing impairment is defined as the loss of sense of hearing, and causes failure by individuals to reach expected levels in academical success, psycho-social improvement, adaptation and information exchange due to flaws in language learning and education (Öztürk, 2006).

Furthermore, there are different definitions for hearing impairment based on the referred area. For example, individuals in need of special education and having hearing deficiency are defined as hearing-impaired (Tüfekçioğlu, 2003, Cited by Etçi, 2013). Hearing impairment has been classified mostly in medical or educational aspects. However, it must also be evaluated in social and cultural aspects and classified as those experiencing hearing impairment (Friend, 2006). Within this regard, in the study conducted by Burcu in 2011, it is stated that disability is a cultural concept, and that such concepts are formed by social and cultural environment of individuals.

\subsection{Physically Handicapped}

Physical disability is defined as any physical condition, including disabilities caused by birth or otherwise arising due to a disease, restraining the individual from achieving the desired educational level (Özer, 2013). Skeletal, muscular and neural system disorders may be experienced before, during or after birth. In such cases, individuals losing physical capabilities to a certain extent, having problems in adapting to the social life and meeting daily needs, and therefore, being in need of protection, care, therapy, counseling and assistance services are called the physically handicapped; and the condition causing such disability is called physical handicap (Uysal, 2013). Those with physical disability and permanent diseases are classified based on the condition causing physical disability 1) Physical disabilities caused by central nervous system damage, 2) Physical disabilities caused by impacts on musculoskeletal system, 3) Congenital physical disabilities and permanent diseases, 4) Permanent diseases and other physical disabilities (Özsoy et al., 2002).

\section{Method}

In this study, relational screening method, which is one of the general screening models, is adopted, stress levels of handicapped sportspeople in the Central Anatolia Region have been examined. These studies are carried out so that such a problem, conditions related to this problem, variables as well as the relationship and differences between variables can be identified (Karasar, 2010).

\subsection{Population and Sampling}

Population of the research consists of elite licensed handicapped sportspeople at the national team level within Central Anatolian Region. And the sample group is comprised of 100 participants selected from this population 
via the convenience sampling.

\subsection{Data Collection Tool}

In this study, in which a general screening model is adopted, the data have been acquired through questionnaires. The questionnaire consists of two parts. The first part is comprised of demographics questions for obtaining personal information. And in the second part, a stress scale has been used so that stress levels experienced with teammates and trainers can be determined. This scale has been adapted from the scale adopted by Odabaşı in 2006 and Yalçın in 2009. The scale consists of 10 statements for determining the stress level. These statements were prepared based on the 5 -point Likert scale, sorted as "never $=1$, rarely $=2$, sometimes $=3$, often $=4$, very often $=5$ ". And reliability of the data has been tested with Cronbach's Alpha coefficient. And Cronbach's Alpha reliability coefficient of the measurement tool has been determined as $\alpha=0.68$ for this research.

\subsection{Data Collection}

In the research, questionnaires were applied by the researcher. Some of the participants were interviewed through face-to-face meetings while questionnaires were sent via mail to others. In this stage, 109 out of the 128 distributed questionnaires were returned, 100 were responded with positive feedback, and 100 questionnaires were included in the research.

\subsection{Data Analysis}

The data attained were, following the necessary storage and control processes, transferred to IBM SPSS 22.0 (The Statistical Program for Social Sciences for Windows) package program. Initially, descriptive statistics were produced. Within this framework, percentage frequency and average prevalence values were examined. Additionally, the normality distribution tests, Kolmogorov-Smirnov and Shapiro-Wilk tests, were carried out in order to determine whether the data initially showed a normal distribution at the analysis stage. Certain descriptive statistics were produced afterwards. The data were determined to have a normal distribution. Therefore, parametric tests were carried out. Independent samples t test was carried out in order to compare stress levels of hearing-impaired and physically handicapped sportspeople and one-way ANOVA was carried out in order to examine the differences in stress levels based on age, education, disability and gender-marital status.

\section{Findings}

\section{Some Descriptive Statistics}

Table 1. Frequency distribution of age variable

\begin{tabular}{lllll}
\hline Variable & & f & $\%$ & Total \\
\hline Age & $21-25$ & 26 & 26 & 100 \\
& $26-30$ & 33 & 33 & \\
& $31-35$ & 20 & 20 & \\
\hline & Other & 21 & 21 & \\
\hline
\end{tabular}

When Table 1 is examined, it is determined that age variable of participants is within a narrow range, and the highest participation is between the ages of 26 and 30 .

Table 2. Frequency distribution of gender and marital status

\begin{tabular}{lllll}
\hline Variable & & f & $\%$ & Total \\
\hline Gender and Marital Status & Married male & 30 & 30 & 100 \\
& Single male & 66 & 66 & \\
& Married female & 1 & 1 & \\
& Single female & 3 & 3 & \\
\hline
\end{tabular}

Table 2 shows the frequency distribution of gender and marital status. When the table is examined, it is seen that most of the participants consisted of men (96\%), and most of the male participants were single (66\%). 
Table 3. Frequency distribution of educational background

\begin{tabular}{lllll}
\hline Variable & & f & $\%$ & Total \\
\hline Educational Background & High school & 47 & 47 & 100 \\
& Associate Degree & 29 & 29 & \\
& Undergraduate Degree & 24 & 24 & \\
\hline
\end{tabular}

Table 3 shows the frequency distribution of educational background variable. When the table is examined, it has been determined that a major part of participants consisted of high school graduates (47\%).

Table 4. Frequency distribution of disability variable

\begin{tabular}{lllll}
\hline Variable & & $\mathrm{f}$ & $\%$ & Total \\
\hline Cause of Disability & Congenital & 52 & 52 & 100 \\
& Accident & 32 & 32 & \\
& Diseases and Other & 16 & 16 & \\
\hline
\end{tabular}

Table 4 shows the frequency distribution of disability variable of the participants. According to the table, most of the participants (52\%) have been congenitally handicapped. It has been further determined that disability of $32 \%$ of the participants was caused by accidents while $16 \%$ was caused by diseases or other reasons.

Table 5. Differences between groups based on scores

\begin{tabular}{|c|c|c|c|c|c|c|c|}
\hline & Group & $\mathrm{N}$ & $\mathrm{X}$ & $\mathrm{S}$ & sd & $\mathrm{T}$ & $\mathrm{p}$ \\
\hline \multirow[t]{2}{*}{ Total Score } & Physically Handicapped & 50 & 27.46 & 5.99 & 98 & -2.76 & $0.00^{*}$ \\
\hline & Hearing-impaired & 50 & 31.02 & 6.88 & & & \\
\hline
\end{tabular}

Note. $\mathrm{p}<0.05$.

Table 5 has been examined in order to determine whether there are significant score differences between groups. When the table was examined, it was found that there is a significant difference between the two groups $(\mathrm{p}=0.00)$ in favor of the $(\mathrm{x}=27.46)$ Physically Handicapped $(\mathrm{p}<0.05)$.

Table 6. ANOVA results based on the difference between age variable and total score

\begin{tabular}{llllll}
\hline & Sum of Squares & Sd & Mean Squares & F & p \\
\hline Total Score & 200.15 & 3 & 66.72 & 1.53 & 0.21 \\
& 4198.09 & 96 & 43.73 & & \\
& 4398.24 & 99 & & & \\
\hline
\end{tabular}

Table 6 was examined in order to determine whether there is a significant difference between age variable and total score. Upon consideration of the table, no significant difference is seen between the age variable and total score $(\mathrm{p}>0.05)$.

Table 7. ANOVA results based on the difference between gender and marital status variable and total score

\begin{tabular}{llllll}
\hline & Sum of Squares & Sd & Mean Squares & F & $\mathrm{p}$ \\
\hline Total Score & 328.84 & 3 & 109.61 & 2.57 & 0.06 \\
& 4069.40 & 96 & 4.39 & & \\
& 4398.24 & 99 & & & \\
\hline
\end{tabular}

When the difference between gender and marital status variable of participants and the total score is examined based on Table 7, no significant difference is seen between gender and marital status variable and total score $(\mathrm{p}>0.05)$. 
Table 8. ANOVA results based on the difference between educational background variable and total score

\begin{tabular}{llllll}
\hline & Sum of Squares & Sd & Mean Squares & F & $\mathrm{p}$ \\
\hline Total Score & 328.84 & 3 & 109.61 & 1.002 & 0.37 \\
& 4069.40 & 96 & 4.39 & & \\
& 4398.24 & 99 & & & \\
\hline
\end{tabular}

Table 8 has been examined in order to determine whether there is a significant difference between educational background variable and total score. Upon consideration of the table, no significant difference is seen between educational background variable and total score ( $p>0.05)$.

Table 9. ANOVA results based on the difference between disability variable and total score

\begin{tabular}{llllll}
\hline & Sum of Squares & Sd & Mean Squares & F & p \\
\hline Total Score & 193.50 & 3 & 96.75 & 2.23 & 0.11 \\
& 4204.74 & 96 & 43.35 & & \\
& 4398.24 & 99 & & & \\
\hline
\end{tabular}

When the difference between disability of participants and the total score is examined based on Table 9, no significant difference is seen between disability variable and total score $(\mathrm{p}>0.05)$.

\section{Discussion and Conclusion}

In this study, stress levels of elite licensed physically handicapped and hearing-impaired sportspeople at the national team level have been examined. Sports is the most significant method adopted for adaptation and rehabilitation of the handicapped. Today, handicapped individuals engage in different sports branches on the basis of the status and degree of their disability. Sports contributes to leading a free life, decreasing the fear of being damaged by the environment of individuals (Civan, Özdemir, Taş, \& Çelik, 2012). The following findings have been attained from analyses within this regard.

A number of descriptive statistics of certain variables were produced, such as standard deviation, maximum value, minimum value, arithmetic mean and total number. Within this regard, it has been determined that majority of the research participants were aged between 26 and 30, mostly consisted of men (96\%), most of whom were single (66\%), a significant number of participants $(47 \%)$ were high school graduates and majority of them were congenitally handicapped.

Similarly, upon analysis of the findings, it is observed that there is a significant difference in total score between the hearing-impaired and the physically handicapped in favor of the latter. In this case, such difference is considered to arise from hearing-impaired individuals having fewer problems in maintaining life-sustaining activities compared to the physically handicapped. In fact, in some studies, it is seen that medical conditions of hearing-impaired individuals do not differ from those of unimpaired individuals. For example, in studies by Keilman et al. (2007) and Rejendran and Roy (2010), it was demonstrated that medical conditions of hearing-impaired children did not differ from those of healthy children.

When the results of the analysis were examined, it was found that there was no significant difference between the variables of age, gender and marital status, educational status and cause of disability. In a study by Gürer et al. (2014), stress levels of physically handicapped and hearing-impaired sportspeople were examined, and no significant difference was determined between the variables of gender, marital status, age, educational background, level of income, occupation, number of children, professional experience and disability. These results are in parallel with our analysis in this study.

In other similar studies, it is seen that sports have an effect on stress level of handicapped individuals. In a research by Lee et al. (2019) on psychological factors in handicapped individuals, high levels of stress and depression causing low self-esteem and self-confidence, negatively affecting the quality of life, were observed (Lee \& Uihlein, 2019).

In the study by Vancini et al. (2009), no significant differences were identified in psychological processes, such as depression, anxiety and state of mind, of wheelchair-bound individuals who are and are not engaged in sports. In this study, the effect of physical activity on functional dependency and quality of life was also systematically analyzed. Upon the analysis of the attained findings, it has been concluded that daily activities have sociological, psychological and physiological positive effects (Vancini et al., 2009). 
And in the research by Civan et al. (2011), long-term anxiety levels of hearing-impaired sportspeople and the sedentary were compared, and it was determined that hearing-impaired individuals who exercised regularly indicated a lower value of long-term anxiety compared to the sedentary. This shows the extent of sports' benefits and effects on the levels of stress of the handicapped, as is for every individual.

As a result, it has been determined that sports affect stress levels positively, there is a significant difference in stress levels of hearing-impaired and physically handicapped sportspeople and there is no significant difference between gender and marital status, educational background and disability.

\section{References}

Akçamete, G., \& Ceber, H. (1999). A comparative review on sociometric status of hearing-impaired and hearing students in inclusive classes. Special Education Journal, 2(3), 64-74.

Altungül, O. (2006). Determining stress levels of those engaging in football activities based on their characteristics. Master Thesis, Frrat University Institute of Medical Sciences, Department of Physical Education and Sports.

Burcu, E. (2011). Cultural definitions on disabled individuals in Turkey: Ankara case. Hacettepe University Literature Journal, 28(1), 37-54.

Civan, A., Özdemir, M., Sarvan, F., \& Civan, Ö. (2011). Comparison of anxiety levels of hearing-impaired sportsmen and sedentary people. International Physical Education and Sports Congress for the Disabled, $16,161-162$.

Çakır, İ. (2006). Comparison of coping methods adopted by Police personnel based on work stress and certain variables. Master Thesis, Çukurova University Institute of Social Sciences, Department of Educational Sciences, Adana.

Civan, A., Özdemir, İ., Taş, İ., \& Çelik, A. (2012). Comparison of state and trait anxiety levels of physically handicapped and nonhandicapped tennis players. Selçuk University Journal of Physical Education and Sports Science, 14(1), 83-87.

Çukur, M. (2001). Organizational stress management (I). OHS Journal of Occupational Health and Safety, 3, $7-$ 10.

Etçi, A. (2013). Relationship between learned strength and hopelessness levels of hearing-impaired students. Unpublished Master Thesis: Yeditepe University Institute of Social Sciences, Istanbul.

Friend, M. (2006). Special education. Contemporary Perspectives for School Professionals. Boston: Allyn and Bacon

Güçlü, N. (2001). Stress management. G.U. Gazi Faculty of Education Journal, 21(1), 91-109.

Gürer, B., Kılınç, Z., Şahin, H. M., \& Esentaş, M. (2014). Examination of stress levels in hearing-impaired and physically handicapped sportspeople based on certain demographical variables. Journal of Academic and Social Science, 2(2), 352-359. https://doi.org/10.16992/ASOS.186

İstengel, A. M. (2006). Examination of the relationship between characteristics and work stress of school advisory teachers. Master Thesis, Marmara University Institute of Educational Sciences Department of Educational Sciences, Istanbul.

Karasar, M. (2010). Scientific Research Method. Ankara: Nobel Publishing, No: 68.

Keilman, A., Limberger, A., \& Mann, M. J. (2007). Psychological and physical well-being in hearing impaired children. Int J Pediatr Otorhinolaryngol, 71(11), 1747-1752. https://doi.org/10.1016/j.ijporl.2007.07.013

Lee, K. K., \& Uihlein, M. J. (2019). Adaptive sports in the rehabilitation of the disabled veterans. Physical Medicine and Rehabilitation Clinics of North America, 30(1), 289-299. https://doi.org/10.1016/j.pmr.2018.08.001

Odabaş1, Z. (2006). Stress in work life (comparison of the personnel in an institutional and a noninstitutional business). Published Master's Thesis. Marmara University Institute of Social Sciences, Istanbul.

Özer, S. D. (2013). Physical education and sports for disabled individuals (4th ed.). Ankara, Nobel Yayın.

Özsoy, Y., Özyürek, M., \& Eripek, S. (2002). Introduction to special education for children in need of special education (12th ed.). Ankara, Kartepe Publishing.

Öztürk, S. (2006). Examination of self-conception in visually impaired and orthopedically handicapped 
elementary students based on their attendance to special education schools or inclusive education. Published Master's Thesis. Hacettepe University Institute of Medical Sciences, Ankara.

Rejandren, V., \& Roy, F. G. (2010). Comparison of health-related quality of life of primary school deaf children with or without motor impairment. Italian Journal of Pediatrics, $36 \quad$ (75), 1-5. https://doi.org/10.1186/1824-7288-36-75

Tüfekçioğlu, U. (2003). Education of children with hearing, speaking and sight problems. Eskişehir: Anadolu University Press.

Uysal, H. (2013). Children in need of special education and special education. students with physical handicap and chronic diseases (I.H. Diken Ed., 7th ed.). Ankara: Pegem Akademi

Vancini, R. L., Gomes, A. A., Paula-Oliveira, H. D., Lira, C. D., Tavares, W. R., Andrade, M. S., \& Viana, R. B. (2009). Quality of life, depression, anxiety symptoms and mood state of wheelchair athletes and non-athletes: A preliminary study. Frontiers in Psychology, 8(13), 1-6.

Yalçın, Y. (2009). Effects of sports satisfaction on stress and aggression levels of sportspeople: an implementation in Antalya province for determining the role of trainer gender. Unpublished Master's Thesis. Erciyes University, Institute of Social Sciences, Department of Sports Management, Kayseri.

\section{Copyrights}

Copyright for this article is retained by the author, with first publication rights granted to the journal.

This is an open-access article distributed under the terms and conditions of the Creative Commons Attribution license (http://creativecommons.org/licenses/by/4.0/). 